\title{
Analysis of the influence of inside and outside water level changes of foundation pit on stability of foundation
}

\author{
Han Shang-yu ${ }^{1, a}$,Yang Kun ${ }^{2, b}$, Wei Xing-xing ${ }^{3, c}$ and,Yun Lei ${ }^{4, d}$,Cheng Cong ${ }^{5, e}$ \\ ${ }^{1}$ College of Civil Construction Nanchang Hang Kong University, Jiangxi Nanchang ;Key Laboratory \\ of water transportation engineering of Ministry of education, Chongqing Jiaotong \\ University,Chongqing \\ 2,3,4,5College of Civil Construction Nanchang Hang Kong University, Jiangxi Nanchang \\ a55932942@qq.com, b68706991@qq.com, c350881738@qq.com, \\ d785410228@qq.com,e547104652@qq.com,
}

\begin{abstract}
Keywords: Foundation pit engineering;Groundwater; Water level change; Steady state;Finite element simulation

Abstract. Inside and outside the foundation pit water level changes often affect the stability of foundation pit.This article is based on the engineering data, the finite element simulation model is established to analyze the relationship between the water level change of the foundation pit and the stability of the foundation pit.The results show that the stability of the foundation pit can be improved by reducing the water level of inside and outside the foundation pit.The Water level inside and outside the pit increase will reduce the stability of the foundation pit. When the water level of the outside of the pit and the inside of the pit is the same, the change of the water level outside the foundation pit have a great influence on the stability of the foundation pit.
\end{abstract}

\section{Introduction}

When the excavation is completed, the steady state of the foundation pit will be affected by the change of the water level inside and outside the pit, especially when the water level in the pit or the outside water level rises abruptly, the stability of the foundation pit will be affected by the water level significantly. The existing engineering data has showed that the change of water level is the main factor affecting the stability of foundation pit.

Scholars have done some research on the influence of groundwater change on the stability of foundation pit.Such as Chen Zuyu [1] proposed and discussed the deep foundation pit engineering practice in the determination of pore water pressure and the scope of application.Li Chun-zhong [2] used the finite element software to study the interaction mechanism of groundwater and soil, and the effect of seepage on foundation pit engineering.Dong Cheng and others [3] through the finite element strength reduction method, compared and analyzed the difference of safety factor of foundation pit overall stability under the static water level conditions, the existence of seepage and the foundation pit outside three kinds of working conditions.Xu Ye-shuang, Shen Shui-long [4] through the finite element simulation analysis, found that the underground water level drawdown, settlement would increase with the depth of the retaining structure and the width of the retaining structure.Wei Jun-jun [5]combined with the actual project to give a consideration of the role of the judge and analyzed the calculation of foundation pit stability calculation formula.Li Yu-qi, Xie Kang-he [6] analyzed the effect of seepage on the water pressure, earth pressure and side pressure of the retaining structure.Zhang Qing-wei [7] simulated and analyzed under unsteady seepage condition, foundation pit surrounding soil and retaining structure deformation and stability.Hu Qi and others[8]had studied the form of seepage failure of soil and the seepage failure mode of foundation pit, and the seepage failure mode of foundation pit was put forward considering the synergistic effect of excavation seepage and retaining structure.

The analysis shows that some scholars have carried out some research on the stability of the foundation pit,which have a great significance to research this paper.However, in the present study, 
the results of comparative study on water level rise and water level rise in pit are less, and the relevant laws need to be further explored.

\section{Simulation analysis model}

\subsection{Model diagram}

A foundation pit excavation shape is rectangle, with a length of $300 \mathrm{~m}$ from east to west and $90 \mathrm{~m}$ from south to north. The total area of foundation pit is $27000 \mathrm{~m}^{2}$ and the excavation depth of foundation pit is $7 \mathrm{~m}$.According to the general plan, the basic map, the geological condition and the distribution of the surrounding buildings and the basis of the form, to determine the row of pile support scheme.The length of row piles is $10 \mathrm{~m}$, the diameter of pile is $0.8 \mathrm{~m}$, the spacing between piles is $1 \mathrm{~m}$. The drilling datum from the site reveal that the water level outside the foundation pit is $2 \mathrm{~m}$ above the ground, and the foundation soil in the foundation pit construction is sandy soil and gravel soil from top to bottom.Based on this, a finite element simulation analysis model is established and see Figure 1.The physical and mechanical parameters of soil are shown in table 1.

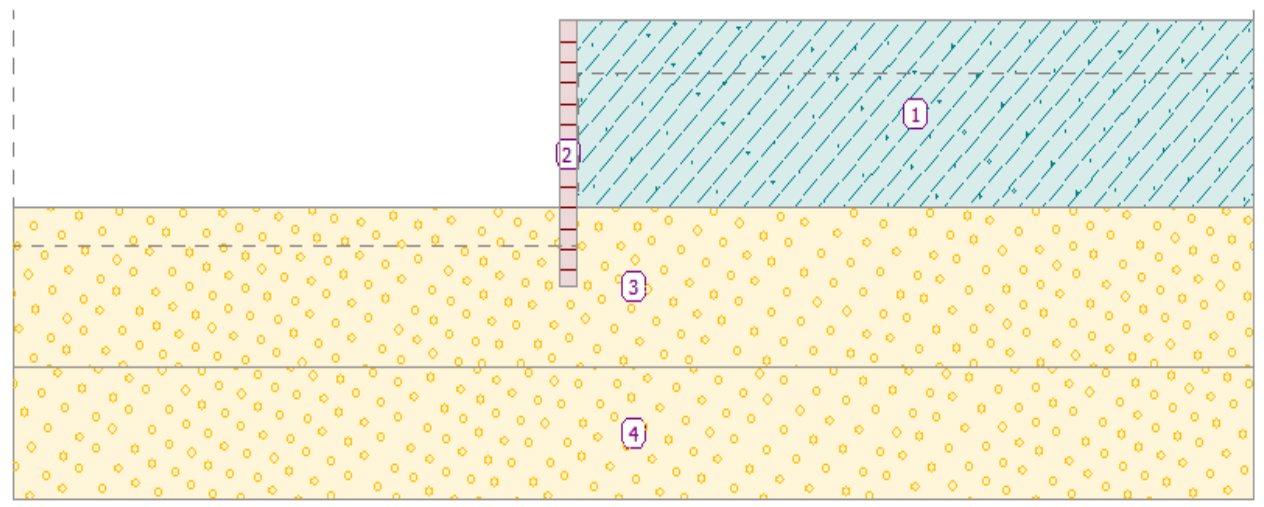

Fig.1 Schematic diagram of the basic model profile

Table 1 Physical and mechanical parameters of model

\begin{tabular}{ccccccc}
\hline $\begin{array}{c}\text { Soil } \\
\text { type }\end{array}$ & $\begin{array}{c}\text { thick } \\
\text { ness } \\
(\mathrm{m})\end{array}$ & $\begin{array}{c}\text { Natural } \\
\text { severe } \\
\gamma \\
\left(\mathrm{kN} / \mathrm{m}^{3}\right. \\
)\end{array}$ & $\begin{array}{c}\text { Saturated } \\
\text { severe } \\
\gamma_{\mathrm{sat}} \\
\left(\mathrm{kN} / \mathrm{m}^{3}\right)\end{array}$ & $\begin{array}{c}\text { Elastic } \\
\text { Modulus } \\
(\mathrm{Mpa})\end{array}$ & $\begin{array}{c}\text { Internal friction } \\
\text { angle } \varphi \\
\left({ }^{\circ}\right)\end{array}$ & $\begin{array}{c}\text { Cohesion c } \\
(\mathrm{kPa})\end{array}$ \\
\hline $\begin{array}{c}\text { Sand } \\
\text { soil }\end{array}$ & $0 \sim 7$ & 20 & 22 & 48 & 36.5 & 0 \\
\hline $\begin{array}{c}\text { Gravel } \\
\text { soil }\end{array}$ & $7 \sim 12$ & 21 & 22 & 289 & 38.5 & 0
\end{tabular}

The inside of the pit using the dewatering well combined with open drain drainage way, after the excavation of foundation pit is completed,analysis of two kinds of working conditions of the change of water level in the pit and the change of water level in foundation pit.

\section{Analysis of groundwater level change on excavation stability.}

3.1 The inside foundation pit water level changes

According to the establish model, under the condition that the outside water level of foundation pit is constant, the change of foundation pit stability state is analyzed in the process of the water height rising and falling of foundation pit.The initial state is that the water level in the pit at the bottom of the foundation pit, the water level difference is $5 \mathrm{~m}$ inside and outside the foundation pit, and the stability safety factor of the foundation pit is 2.16 . 
Analysis, assuming that foundation pit lateral water level remains the same,simulate separately:the steady state of foundation pit when water in the pit, and the water to the stable state above the bottom of the foundation pit $1.5 \mathrm{~m}$; and the influence of the stability of the foundation pit on the safety factor when the water level in the foundation pit dropped from $1.5 \mathrm{~m}$ above the bottom of the foundation pit to the bottom of the pit. The simulation results are shown in Fig.2:

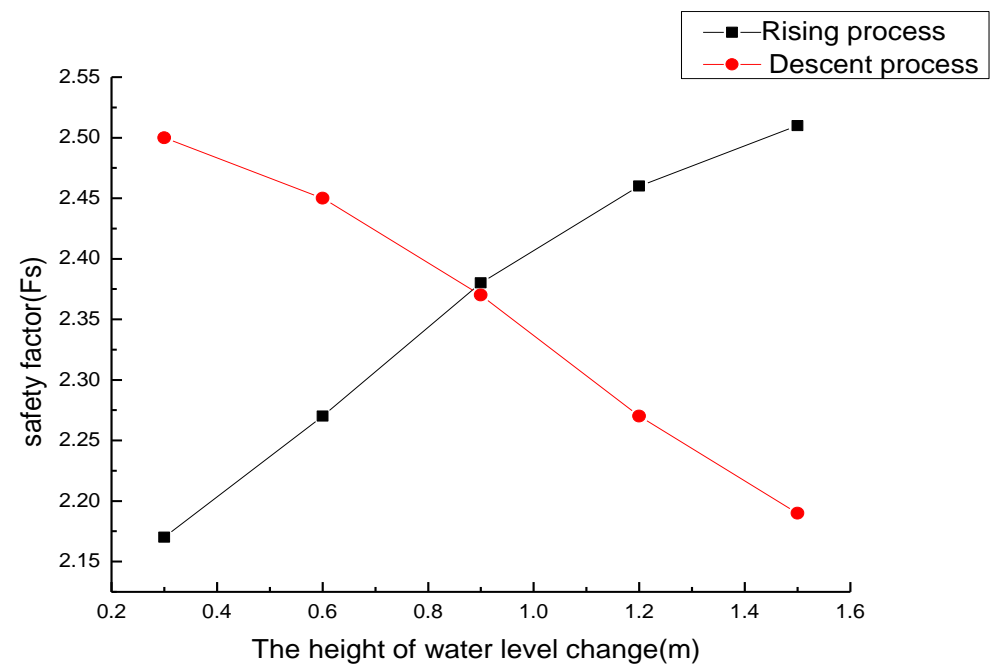

Fig. 2 Influence of water level change on safety factor in the inside foundation pit

Figure 2 illustrates the foundation pit water level change has a large influence on the safety factor of foundation pit Fs. When the water level rises in the foundation pit, the safety factor increases with the increase of the water height. When the water height is $1.5 \mathrm{~m}$, the safety factor increases from 2.17 to 2.51 , and the variation range is close to $15 \%$. This is mainly due to foundation pit lateral to the coarse grained soil, water content change has little influence on the strength index, rising water level in the pit side wall can reduce the water pressure and seepage force unfavorable effects on the stability of foundation pit state, so that the sliding force is reduced, the stability of foundation pit safety coefficient becomes larger. When the water in the pit is

drained, the water level in the pit falls suddenly, and the water outside the foundation pit can generate the penetration force and the sliding force to the pit, which has a negative effect on the stability of foundation pit, and the safety factor of foundation pit is reduced.

3.2 The outside foundation pit water level changes

According to the model, the water level in the pit bottom below $1.5 \mathrm{~m}$, the water level difference inside and outside the foundation pit is $6.5 \mathrm{~m}$, the initial safety factor of foundation pit is 1.9. To keep the inner water level of foundation pit unchanged, the change of foundation pit safety factor is simulated and analyzed when the water level of pit is increased by $1.5 \mathrm{~m}$ and decreased by $1.5 \mathrm{~m}$ under $2 \mathrm{~m}$. The simulation results are shown in Figure 3 


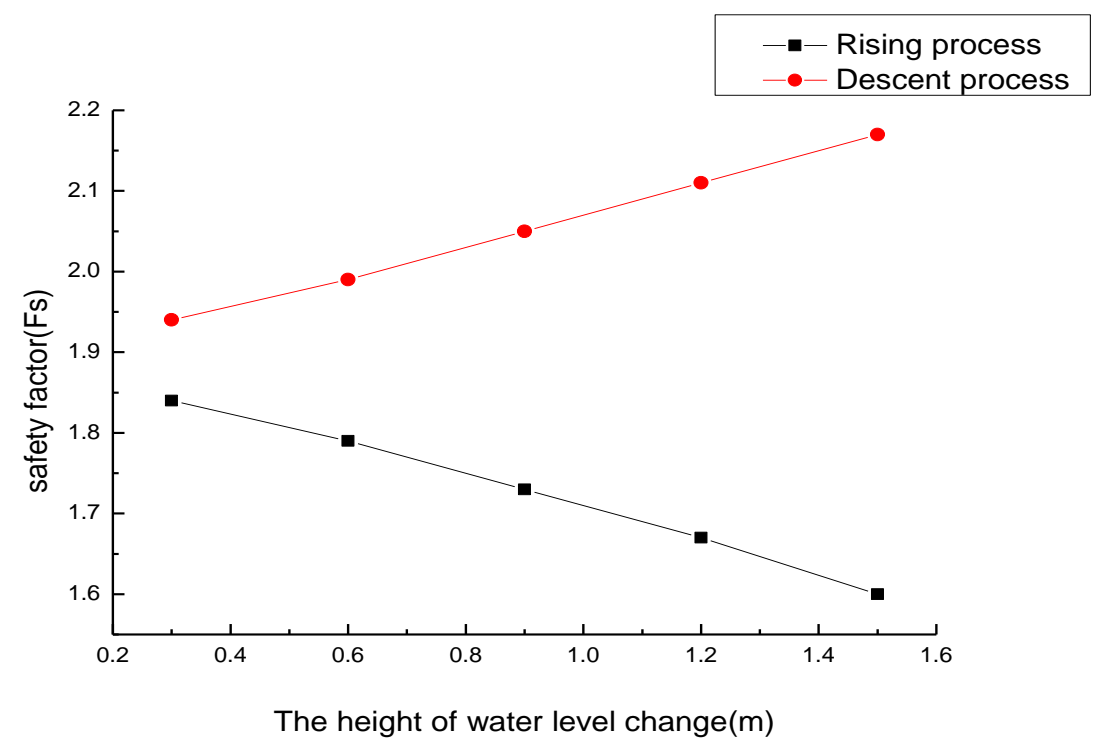

Fig. 3 Influence of water level change on safety factor in the outside foundation pit

From Figure 3 we can see that the water level change on the outside of the foundation pit has a great influence on the safety factor Fs of the foundation pit. When the water level rises, the safety factor is reduced from 1.9 to 1.6 , the reduction rate is about $16 \%$. When the water level drops, the safety factor is increased from 1.9 to 2.17 , and the increase is close to $15 \%$. This is mainly due to the change of the water level outside the foundation pit, will directly change the size of the lateral seepage force of foundation pit and the direction of penetration, as well as the side of foundation pit downward force, and then the stability of the foundation pit influence.

\section{4 conclusions}

With the aid of the finite element analysis model, this paper analyzes the change of the foundation pit stability when the water level changes in the foundation pit, the main conclusions are as follows:

(1)The change of the water level inside the foundation pit can change the sliding force and seepage force, and then have a significant impact on the stability of the foundation pit.

(2)The increase of the height of water in the pit and the decrease of the water level in the pit will enhance the stability of the foundation pit to a certain extent, otherwise it will reduce the stability of the foundation pit.

(3)After the excavation of foundation pit, the water level of foundation pit and the inner water of foundation pit should be strictly controlled, so as to reduce the adverse effect of the change of water level in foundation pit on the stability of foundation pit.

\section{References}

[1] Chen Zu-yu. Discussion on several problems in stability analysis of deep foundation pit [J]. Chinese Journal of geotechnical engineering, 2010, S1 (S1): 1-8.

[2] Li Chun-zhong. Study on the stability of foundation pit slope under the action of groundwater seepage [D].Nanjing University of Technology, 2006

[3] Dong Cheng, Zheng Ying-ren, Tang Xiao-song. Stability analysis of foundation pit under seepage condition using finite element strength reduction method [J]. Journal of civil engineering, 2009,42 (3): 105-110.

[4] Xu Ye-shuang, Shen Shu-long, Ma lei. The blocking effect of underground structures on the seepage of underground water [J]. Journal of Zhejiang University (Engineering Science), 2010, 44 (10): 1902-1906.

[5] Wei Jun-Jun, Zhang Li-wei. Analysis of foundation pit seepage stability [J]. Journal of water conservancy and civil engineering, 2012,10 (3): 79-82. pressure 
[6] Li Yu-qi Xie Kang-he. Stability analysis of foundation pit retaining structure considering seepage effect [J]. "Science Bulletin", 2005, 21 (4): 440-444.

[7] Zhang Qing-wei. Stability analysis of foundation pit support structure under unsteady seepage flow [D]. Zhengzhou: Zhengzhou University, 2007

[8] Hu Qi, Ling Dao-Sheng. The failure mechanism and its influence on [J]. rock and soil mechanics, seepage of silty sand foundation soil in the deep foundation pit engineering 2008,29(11)2967-2972. 